\title{
Zonas con Potencial para el Pago de Servicios Ambientales en el Valle del Mezquital, Hidalgo
}

\section{Zones with Potential for the Payment of Environmental Services in the Valle del Mezquital, Hidalgo}

\author{
Genaro Aguilar-Sánchez \\ g_aguila@correo.chapingo.mx @ https://orcid.org/0000-0003-1518-0801 \\ Reynol González-Vizcarra \\ canas_X@hotmail.com @ https://orcid.org/0000-0002-4983-3164 \\ Universidad Autónoma Chapingo (México) \\ Carretera México-Texcoco, Km 38.5, Chapingo, municipio de Texcoco, Estado de México,
} México. 56230

\section{INFO ARTÍCULO}

Recibido: $21 / 3 / 2018$

Revisado:13/6/2019

Aceptado: 25/6/2019

\section{PALABRAS CLAVE}

Servicios ambientales

Valle del Mezquital

SIG

Facetas

\section{KEYWORDS}

Environmental services

Mezquital Valley

SIG

Facets

\section{RESUMEN}

Las regiones áridas en México, están excluidas de los beneficios del esquema de Pago por Servicios Ambientales (PSA), de la Comisión Nacional Forestal, debido a la poca cubierta forestal que estas tienen. El objetivo del trabajo es realizar una identificación a nivel regional de aquellas zonas potenciales de pago por servicios ambientales en el Valle de Mezquital, estado de Hidalgo. La limitante de zona árida es la principal justificación para que se generen propuestas como alternativas para tratar de incluir dichas regiones en el PSA. La identificación de zonas elegibles o prioritarias para el PSA se basó en las metodologías del Levantamiento Fisiográfico, para delimitar las áreas o unidades ambientales y, para el análisis de la toma de decisiones el Multicriterio. Se identificaron las áreas prioritarias para el pago por servicios ambientales equivalentes a 911 ha, con características de riesgo alto y muy alto de perder los servicios ecosistémicos provistos por la conservación de la biodiversidad.

\begin{abstract}
The arid regions in Mexico are excluded from the benefits of the Payment for Environmental Services (PES) scheme of the National Forestry Commission, due to the low forest cover they have. The objective of the work is to carry out an identification at the regional level of those potential payment zones for environmental services in the Mezquital Valley, Hidalgo State. The limitation of the arid zone is the main justification for generating proposals as alternatives to try to include these regions in the PSA. The identification of eligible or priority areas for the PSA was based on the methodologies of the Physiographic Survey, to delimit the environmental areas or units and, for the analysis of decision-making, the Multicriteria. Priority areas for payment for environmental services equivalent to 911 ha were identified, with high and very high risk characteristics of losing the ecosystem services provided by the conservation of biodiversity.
\end{abstract}




\section{INTRODUCCIÓN}

De acuerdo con la Ley General de Desarrollo Forestal Sustentable de México, los servicios ambientales están definidos como los que brindan los ecosistemas forestales de manera natural o por medio del manejo sustentable de los recursos forestales, tales como: la provisión del agua en calidad cantidad; la captura de carbono, de contaminantes y componentes naturales; la generación de oxígeno; el amortiguamiento del impacto de los fenómenos naturales; la modulación o regulación climática; la protección de la biodiversidad, de los ecosistemas y formas de vida; la protección y recuperación de suelos; el paisaje y la recreación, entre otros (DOF, 2009).

La relación que existe entre los bosques, la sociedad y la provisión ecosistémica que éstos proporcionan han pasado por varias modificaciones a lo largo del tiempo. Se habla, de la incorporación de nuevos conceptos para valorar a los bosques. Lo anterior ha dado la pauta para brindar alternativas y nuevos conocimientos en el campo de la ciencia y la tecnología, aplicadas por las ciencias forestales (Gómez J., Monterroso A., y Espejel de la Rosa, S. 2007).

Se estima que más del $30 \%$ de la superficie del planeta está cubierta por bosque (FAO, 2005), aunado a esto se agrega el alto valor de importancia para la vida en todo el globo. Sin duda existe un alto valor asociado a la conservación de la mega diversidad florística y faunística que estos albergan, más estrechamente a los bosques de las regiones tropicales del continente americano. Por otro lado, se ha estimado que los ecosistemas forestales albergan más del $70 \%$ de las especies a nivel mundial (Groombridge, B., 1992). Derivado de lo anterior, es imposible prescindir de la cubierta forestal que los bosques nos proporcionan, dado que son el motor de vida de los seres humanos. Sin embargo, no solo los ecosistemas forestales son los únicos que existen en nuestro planeta, las regiones áridas y semiáridas albergan una proporción menor, pero no menos importante de las especies animales y vegetales del mundo.

En México los servicios ambientales han recibido cada vez mayor atención, tal es el caso de los esquemas de pago para la protección de los mismos. Derivado de esto, desde el año 2003, se implementó el programa de Pago por Servicios Ambientales (PSA) el cual funciona dentro de un esquema a nivel nacional que brinda el financiamiento para dicho propósito. Para el caso de México, el órgano de gobierno encargado de llevar a cabo la dirección y ejecución de éste es la Comisión Nacional Forestal (Diario Oficial de la Federación 2009). En algunos casos, con el pago se busca que los usuarios del suelo adopten prácticas de uso que garanticen la provisión de un servicio en particular, por ejemplo, plantar árboles con fines de secuestro de carbono, entre otros (CIFOR, 2007).

Los esquemas de pago tratan que los beneficiarios directos o indirectos de los Servicios Ambientales, $\mathrm{SA}$, paguen de manera directa, contractual y condicionada a los propietarios proveedores de SA locales por adoptar prácticas que aseguren la conservación, protección y restauración de ecosistemas y los SA que estos generan (Wunder, S., 2006). Sin embargo, los criterios metodológicos que rigen la selección de los ecosistemas o regiones que son propensas a entrar en dichos esquemas de pago son iguales para todo el territorio. Estos están muy por debajo de los criterios de selección definidos por las reglas de operación que para este fin promueve la Comisión Nacional Forestal, (CONAFOR 2012), entre lo que destaca que serán zonas elegibles aquellas superficies propuestas que su cubierta forestal sea mayor al $50 \%$.

En este sentido, se debe comprender que las nuevas propuestas metodológicas que solo atañen a las zonas áridas, son para que las identificaciones de zonas elegibles sean exclusivas de estas características climáticas, y su definición y delimitación territorial abarquen la diversidad de flora y fauna que en ellas se encuentran. De este modo, se debe hacer énfasis en que la correcta evaluación de los servicios ecosistémicos debe producir mejores resultados en la identificación de los sitios donde estos residen, cuantificar si existe cambio de uso del suelo y su probable impacto en la provisión de los servicios y así valorar los beneficios derivados de estos servicios a las poblaciones humanas cercanas y distantes (Naidu, et al., 2006).

En este contexto, el objetivo del presente trabajo es realizar una identificación, a nivel regional, de aqueIlas zonas potenciales de pago por servicios ambientales en el Valle de Mezquital, estado de Hidalgo (Méxi$\mathrm{co})$. 


\section{2. ÁREA DE ESTUDIO}

La Unidad de Manejo Forestal (UMAFOR) "1304-Valle del Mezquital", la cual por extensión territorial ocupa el primer lugar dentro del estado de Hidalgo, por relación con las otras cuatro unidades de manejo que lo conforman, y tiene una superficie total de 642.654 hectáreas. Se localiza al suroeste del estado de Hidalgo, entre las coordenadas extremas $20^{\circ} 42^{\prime} 19,98^{\prime \prime}$ y $19^{\circ} 46^{\prime} 09,81^{\prime \prime}$ de latitud norte, y $99^{\circ} 51^{\prime} 06^{\prime \prime}$ y $98^{\circ} 46^{\prime} 44.48^{\prime \prime}$ de longitud oeste (mapa 1).

El valle del Mezquital, Hidalgo, abarca 28 municipios (INEGI, 2005) lo que representa aproximadamente el $34 \%$ de la superficie del estado de Hidalgo y constituye un área de gran importancia ecológica, económica, social, histórica y cultural, que se caracteriza por sus diversas condiciones ambientales lo que ocasiona que se presenten gradientes ecológicos que favorecen la presencia de diversos hábitats. Las variantes altitudinales, fisiográficas, de geología y suelo influyen de manera decisiva en el establecimiento de varias formas de vida y en el desarrollo de una gran riqueza específica, lo que genera diversidad de vegetación con un amplio potencial de recursos para la zona.

\subsection{Aspectos Físicos}

- Clima. En el territorio de esta unidad se ubican dos grandes grupos de climas, los templados con menor proporción, y en mayor proporción los semisecos, BS, con precipitación de 400 a 600 mm anuales

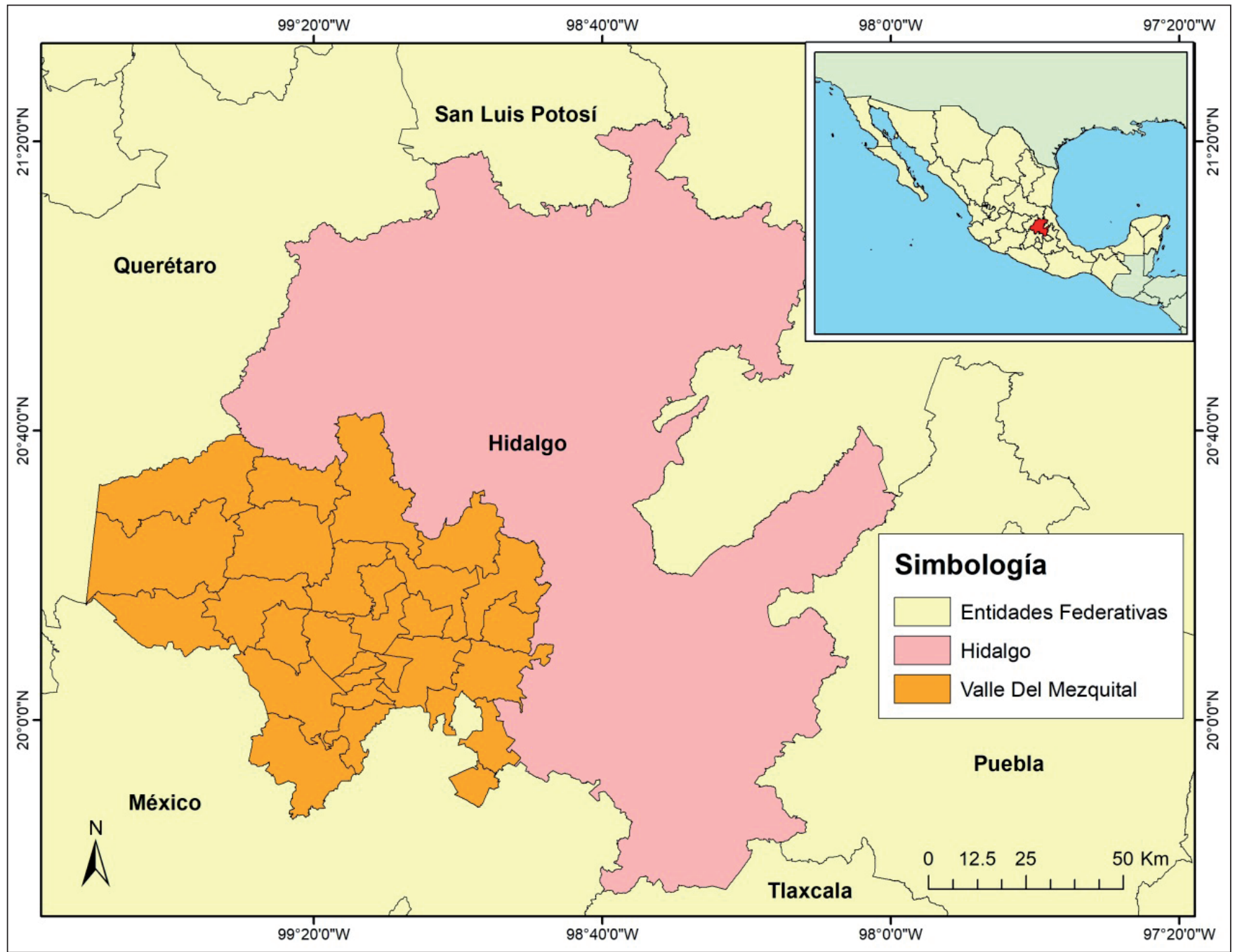

Mapa 1. Ubicación del Valle del Mezquital, estado de Hidalgo. Fuente: Elaboración propia. INEGI, 2005. 
y temperatura media de $18^{\circ} \mathrm{C}$. El clima semiseco es el más común en la mayoría de los municipios. Dada la condición climática de la Unidad se pueden prever también las condiciones de vegetación, tomando el clima como el principal factor para el desarrollo de los niveles de vegetación.

- Geología y geomorfología. La Unidad de manejo forestal se ubica en el Altiplano Mexicano, dentro de la provincia fisiográfica denominada Eje Neovolcánico, en donde forma un amplio valle dividido por serranías y cerros separados. En el área afloran rocas de tipo sedimentario e ígneo que varían en edad y composición.

- Suelos. En la UMAFOR inciden ocho diferentes unidades de suelo de acuerdo con la clasificación FAO - UNESCO. Los tipos de suelo son: cambisol (B), Feozem (H), Litosol (I), Luvisol (L), Planosol (W), Rendzina (E), Vertisol (V) (INEGI, 1992).

- Hidrología. El área de estudio pertenece en su generalidad a la Región Hidrológica No. 26, Parcial, Alto Pánuco, Cuenca del río Tula. Desde el punto de vista administrativo, tanto la Cuenca del Valle de México como la de Tula, quedaron integradas al Consejo de Cuenca del Valle de México. (CONAGUA, 2015) - Vegetación. La vegetación está descrita de acuerdo con la clasificación de Rzedowsky (2006) como Matorral Xerófilo. Entre las principales características fisonómicas y estructurales abarca comunidades de fisonomías muy diversas, características de las zonas áridas y semiáridas. Incluye comunidades, en las que predominan arbustos altos o árboles bajos de 3 a $5 \mathrm{~m}$ de altura, caducifolios (generalmente por un periodo breve durante la época de secas), con hojas o foliolos de tamaño pequeño. Los matorrales crasicaules son comunidades arbustivas dominadas por plantas de tallo suculento (cactáceas grandes); la altura depende de la especie que lo conforma y puede ser hasta de $10 \mathrm{~m}$. En los matorrales rosetófilos predominan especies arbustivas o subarbustivas de hojas alargadas y angostas agrupadas en forma de roseta; el estrato subarbustivo espinoso y perennifolio a menudo es muy denso. Los bosques de Yucca (izotales) llegan a medir de 2 a $4 \mathrm{~m}$ de alto.

En el matorral micrófilo predominan elementos arbustivos de hoja o foliolo pequeño; de altura variable ( 1 a $3 \mathrm{~m}$, con eminencias aisladas de hasta $6 \mathrm{~m}$ ) de acuerdo a su composición florística y las condiciones ambientales.

El pastizal está formado por comunidades vegetales en las que el papel preponderante corresponde a las gramíneas (i.e. estrato herbáceo dominante). Comprende las comunidades denominadas zacatonales, páramos de altura y sabanas. La altura media es de 20 a $70 \mathrm{~cm}$, aunque se mantienen casi siempre mucho más bajos a causa del pastoreo. La cobertura frecuentemente es menor del $50 \%$ y rara vez supera el $80 \%$. Las sabanas están constituidas por praderas de gramíneas sin árboles o con árboles esparcidos. En general las gramíneas son amacolladas, ásperas y resistentes a las quemas periódicas.

A fin de simplificar el análisis de la distribución de las especies en los tipos de vegetación, se agruparon éstos de la siguiente manera: como Matorrales, el Matorral crasicaule, Matorral desértico, y el Matorral submontano; y como Bosques templados mixtos, el Bosque de encino, el Bosque de junípero, el Bosque de encino junípero y el Bosque de pino-encino. Se consideraron los registros de zonas agrícolas o campos de cultivo y de pastizales como registros de áreas perturbadas por igual, ya que se consideró que el pastizal es inducido en la mayoría de los casos.

\section{MARCO CONCEPTUAL}

\subsection{La provisión de los servicios ecosistémicos y la estimación de valor}

Los servicios ecosistémicos son los que integran beneficios, tangibles e intangibles, que proporciona el medio natural para que sean aprovechados por el ser humano y de acuerdo a ciertos criterios, pueden ser valorados en términos económicos a fin de equipararlos con actividades económicas que implican cambios en los usos de suelo y de esta manera contar con argumentos adicionales para su conservación y manejo (Camacho, 2011). Se puede definir y clasificar a los servicios ecosistémicos de acuerdo a su importancia y valor de provisión: 
- Funciones de regulación: Son los que están relacionados con la capacidad de regular procesos ecológicos esenciales y sostener sistemas vitales a través de ciclos biogeoquímicos y otros procesos biológicos.

- Funciones de hábitat: De forma natural los ecosistemas proporcionan hábitat de refugio y reproducción para flora y fauna contribuyendo a la conservación biológica y diversidad genética. Estas funciones proporcionan servicios como mantenimiento de la diversidad biológica y genética, y de especies comercialmente aprovechables.

- Funciones de producción: Son los que intervienen en los procesos fotosintéticos y autótrofos en general, a partir de los cuales los organismos autoabastecen sus requerimientos orgánicos a partir de compuestos inorgánicos y que también son sustento de consumidores de distinto orden, para generar una mayor variedad de biomasa. Esta variedad de estructuras proporciona una variedad de bienes y servicios para consumo humano, que van desde alimento y materia prima hasta recursos energéticos y medicinales.

- Funciones de información: Los ecosistemas proporcionan funciones de referencia y contribuyen al mantenimiento de la salud humana, proporcionando oportunidades de enriquecimiento espiritual, desarrollo cognitivo, recreación y experiencias estéticas (paisaje).

- Desde hace mucho tiempo, los ecologistas siempre han manifestado como la naturaleza provee los servicios que mantienen la vida en la tierra a cualquier escala, a su vez muchos servicios no tienen un precio en el mercado y muchos de estos servicios son irremplazables por la tecnología (Constanza et al. 1997). Por tanto, un servicio ambiental es utilizado para entender que la estructura y función de la naturaleza tiene un valor y que las funciones de los ecosistemas pueden redefinirse como servicios y bienes ambientales, cuando se considera el valor que tienen para los seres humanos.

Por otro lado, es bien sabido que las relaciones que existen entre las políticas ambientales y la obtención de satisfactores no es completamente compatible, deriva en que la relación entre el manejo de la tierra y los servicios ambientales no es completamente conocida y muy poco estudiada (Campos, 2005). En este sentido, tratar de dar valor a los servicios ambientales es un problema grave dado que no son procesos definidos con principio y fin establecidos, sin embargo, es necesario tratar de hacerlo para poder determinar los esquemas de PSA.

En el intento por valorar los servicios ambientales, los desarrollos de las políticas solo consideran valores mixtos (Faber, 2005), sin considerar las externalidades que se generan en la obtención y aprovechamiento de los satisfactores que estos proporcionan.

\subsection{Los esquemas de pago por Servicios Ambientales}

De acuerdo con la Ley General de Desarrollo Forestal Sustentable de México, los servicios ambientales están definidos como los que brindan los ecosistemas forestales de manera natural o por medio del manejo sustentable de los recursos forestales, tales como: la provisión del agua en calidad y cantidad; la captura de carbono, de contaminantes y componentes naturales; la generación de oxígeno; el amortiguamiento del impacto de los fenómenos naturales; la modulación o regulación climática; la protección de la biodiversidad, de los ecosistemas y formas de vida; la protección y recuperación de suelos; el paisaje y la recreación, entre otros (DOF, 2011).

En este sentido, el pago por servicios ambientales (PSA) es una clase de instrumento económico diseñado para dar incentivos a los usuarios del suelo, de manera que continúen ofreciendo un servicio ambiental (ecológico) que beneficia a la sociedad como un todo. En algunos casos, con el pago se busca que los usuarios del suelo adopten prácticas de uso que garanticen la provisión de un servicio en particular, por ejemplo, plantar árboles con fines de almacenar carbono, entre otros (CIFOR, 2006).

Otra definición de esquema de pago por servicios ambientales es que se trata de un mecanismo flexible y adaptable a diferentes condiciones, que apunta a un pago o compensación directa por el mantenimiento o 
provisión de un servicio ambiental por parte de los usuarios del servicio del cual se destina a los proveedores (Pagiola et al. 2006).

Si bien es cierto que los esquemas de pago por servicios ambientales están tomando un lugar importante en las políticas públicas orientadas a la protección de recursos naturales, es importante mencionar que la definición de la misma toma en cuenta criterios que son por lo general verticales y generalizan la aplicación de los recursos. En este mismo sentido, la definición de las políticas toma un sentido estructural un tanto complicada, ya que existen sectores de la sociedad que ven un tanto irreverente poner un precio a los componentes de la naturaleza, ya que esto ha provocado serios problemas de carácter técnico y hasta cierto punto ha levantado críticas que son de origen cultural (Pagiola, 2006).

De esta manera, en el diseño de la estrategia de política pública para proteger los servicios ambientales, encontramos tres opciones:

1. Apoyar el surgimiento de mercados privados, un ejemplo de este enfoque es el ecoturismo, el café de sombra certificado, proyectos de bonos de captura de carbono, los contratos de servidumbres ecológicas, comprar los derechos a cambiar la vegetación natural, etc.

2. Recibir transferencias de los beneficiarios globales, por ejemplo los apoyos del Fondo para el Medio Ambiente Mundial.

3. Actuar como intermediarios, cobrando a los beneficiarios locales y pagando a los propietarios de los bosques. El esquema de Pago por Servicios Ambientales (PSA) en México, ha sido un esfuerzo llevado a cabo por la Comisión Nacional Forestal (CONAFOR) y diversos Socios importantes como la Comisión Nacional de Áreas Naturales Protegidas (CONANP). Este programa, tiene como finalidad impulsar el reconocimiento del valor de los servicios ambientales que proporcionan los ecosistemas forestales, agroforestales y recursos naturales, además de apoyar la creación de mercados de estos servicios. Estos programas apoyan a comunidades, ejidos, Asociaciones Regionales de Silvicultores y a propietarios de terrenos forestales. El Programa y las reglas de operación de ProÁrbol de México, han pasado por una serie de modificaciones y actualmente los conceptos de apoyo se agrupan en cinco categorías siendo (CONAMP, 2010): Hidrológicos, Biodiversidad, Sistemas agroforestales, Captura de carbono y Elaboración de proyectos.

En el año 2003 la CONAFOR creó el Programa de Pago de Servicios Ambientales Hidrológicos (PSAH) y un año después, en 2004 se creó el Programa para Desarrollar el Mercado de Servicios Ambientales por Captura de Carbono y los Derivados de la Biodiversidad y para Fomentar el Establecimiento y Mejoramiento de Sistemas Agroforestales (PSA-CABSA) (Diario Oficial de la Federación 2009). Aunque a partir del año 2010, la CONAFOR retiró la modalidad de Pago por servicios ambientales por Captura de Carbono, quedando únicamente las modalidades para: 1) Servicios ambientales hidrológicos y 2) Derivados de la Biodiversidad (incluyendo el establecimiento y mejoramiento de Sistemas Agroforestales). (Diario Oficial de la Federación, 2009).

El esquema de PSA mexicano, lo que trata es obtener el máximo beneficio ambiental en la selección de predios a través de una serie de criterios (Pagiola, 2008). Entre los criterios que tiene CONAFOR para seleccionar los predios (terrenos) beneficiados para PSA en ambas modalidades (Hidrológicos y Biodiversidad) se encuentran (Diario Oficial de la Federación 2009): estar dentro de un Área Natural Protegida; estar incluido dentro de las 60 montañas prioritarias para CONAFOR; ubicarse dentro de la microcuenca donde haya una zona elegible para PSA; estar conformado por un comité de vigilancia acreditado por la Procuraduría Federal de Protección al Ambiente (PROFEPA), si el predio se une con otros predios para formar corredores biológicos, si bien si se demuestra que es un usuario el propietario de los servicios ambientales pagará por estos; tener un predio con Ordenamiento Territorial Aprobado; encontrarse en una zona con riesgo de deforestación y contener alta densidad de biomasa. 


\subsection{Experiencias del Pago de Servicios ambientales, PSA}

El tema del PSA, tiene antecedentes en diversos países del mundo, por ejemplo, en Ecuador Chafa P. y Cerón P (2016), en su trabajo sobre PSA para conservar el agua, obtuvieron buenos resultados en la construcción de un fondo para protección del agua.

Por otra parte, Macip-Ríos R. y Macip R. F. (2013), investigaron sobre pago por servicios ambientales (ecosistémicos) en México y al interrogarse sobre si estos son eran una alternativa para la conservación de la biodiversidad y el desarrollo, observaron preliminarmente como entre el índice de desarrollo humano (IDH) y el PSA, a escala nacional y estatal (Estados de Puebla, Veracruz y Oaxaca, entre otros), se evidencia una relación negativa. Sin embargo, indican que a nivel local es necesario para generar conclusiones más precisas e insisten en el hecho de que los esquemas de PSA en México deben considerarse aún en proceso experimental y no como herramienta para la conservación de referencia.

También, Rojas-López O., González- Guillen M., Gómez-Guerrero M. y Romo Lozano. J., (2012) indagaron sobre la renta de la tierra y el pago de servicios ambientales en la Sierra norte de Puebla. En este caso, los estudios realizados mostraron que el Pago por Servicios Ambientales Hidrológicos (PSAH) no había sido exitoso dentro del área de estudio. Se entiende así que para que este sistema hubiese resultado atractivo a los propietarios forestales se les debería haber compensado con al menos $\$ 1.516,50$ ha/año, cantidad que representa el costo de oportunidad (CO) de los terrenos con uso potencial forestal que pueda obtenerse por el uso pecuario; mientras que el CO para los usos agrícola y pecuario correspondió a $\$ 1,829.50$ ha/año que pudiera obtenerse por el uso forestal. El estudio reveló que los suelos con un bajo uso potencial forestal presentan características de productividad superior y son más aptos para brindar mayor diversidad de servicios ambientales, en contraste con aquellos terrenos que sustentan usos agrícolas y pecuarios. Por tanto, además de la renta de la tierra forestal y de los beneficios derivados de alguna actividad que soporte, es importante que el PSAH considere los costos de los impactos ambientales que se pueden producir ante un cambio de uso potencial de la tierra.

Otros investigadores han realizado trabajos en México. Así, Gómez J., Monterroso A. y Espejel de la Rosa, S. (2007) investigaron sobre la captura de carbono como servicio ambiental en la comunidad "Lobos y Pescadores"del Municipio de Tepehuanes, Durango. Este trabajo concluye que las áreas de mayor potencial de contenido de carbono son las que son manejadas por el Programa del Manejo Forestal de la Comunidad, ya que ahí se tienen las mejores características naturales, para el crecimiento de los árboles. Dentro del conjunto de la vegetación, el género que tiene más contenido de carbono es el Pinus con un tallo de 30 centímetros de grosor.

Por último, referir los trabajos de Sánchez, A., García, R. Ma y Palma, A. (2007). Estos hicieron análisis de algunas experiencias relacionadas con el Pago de Servicios Ambientales Hidrológicos en México. Ellos evidenciaron como el valor total de los pagos de SAH en las áreas analizadas es modesto, pero significativo para los productores forestales de bajos ingresos. Además, indican la necesidad de establecer tarifas equitativas, para lograr una mayor equidad.

Con todo, cabe resaltar como el PSA, y el PSAH, aunque en diferentes espacios, han sido importantes al contribuir tanto a la preservación y conservación de los recursos naturales, como del suelo, vegetación y el agua. Sin embargo, se pone de manifiesto como para conseguir una compensación económica suficiente por estos servicios, es necesario incrementar el pago, a los ejidatarios, comuneros y pequeños propietarios, en tanto contribuiría en gran medida lograr ese otro gran reto que no es otro sino conseguir a mejorar el nivel de vida de la población local de estos ámbitos.

\subsection{Alcances del PSA en México}

Según cifras derivadas del Inventario Nacional Forestal y de Suelos 2004-2009 (CONAFOR, 2012) México cuenta con una superficie de bosques y selvas de aproximadamente unas 63, 411,754.04 ha, mientras que de zonas áridas y semiáridas tiene unas 56.929.256,33 ha. La superficie destinada total de zonas elegibles para el PSA asciende a unas 48.64 .000 ha, divididas en seis áreas de Pago. 
De acuerdo con las reglas de operación del programa denominado ProÁrbol, las áreas de PSA diferenciado se dividen en seis áreas; correspondiendo al área I, II y III, los apoyos para Servicios Ambientales Hidrológicos, mientras las áreas IV, V y VI los apoyos para Servicios ambientales derivados de la Conservación de la Biodiversidad. De este modo y de acuerdo con las superficies, las áreas destinadas a protección de la Biodiversidad suman un total de 28.826 .712 hectáreas, consideradas solo dentro de zonas con cubierta forestal, siendo en este sentido insuficiente para cubrir el resto de la superficie que no cuenta con características necesarias para su integración.

Los criterios de selección y determinación de las áreas, son de aplicación general para todas las regiones del país, sin embargo, esto afecta directamente a las zonas que no cuentan con características de selección aplicables. Aun con este argumento existen expertos, quienes piensan que los criterios de decisión para la delimitación de las áreas elegibles no deben cambiar, sino que deberían ser un tanto más rigurosos y exactos en su aplicación, es decir, que estén en acordes a su conexión directa con la definición de mecanismo de PSA y que se apliquen según la lógica de su funcionamiento, pues a pesar de contar con dichos criterios, en nuestro país se tiende a emplear este tipo de apoyos como un mecanismo político de combate a la pobreza y desigualdad de género, ya que las áreas manejadas por mujeres tienen prioridad. Aunado a esto se tiene que en el esquema de PSA, ni la directriz firme de sus objetivos, está garantizada debido a la deficiencia en su legislación y las fluctuaciones en las corrientes políticas sexenales (COLPOS, 2007).

\section{METODOLOGÍA}

En el presente trabajo se considera que el uso de metodologías combinadas derivadas de la observación simple y la ayuda de los Sistemas de Información Geográfica (SIG) ayudan a definir mejor las áreas importantes, para PSA, de las regiones semiáridas y áridas. Ancira (2015) y Valdez (2011) respaldan la veracidad de los resultados al usar imágenes satelitales combinado con los SIG.

La identificación de zonas elegibles o prioritarias para el PSA se basó en gran medida en la combinación de la metodología utilizada por Imbach, I., (2005) y Chuvieco, E. (2000). En la que se explica mediante la utilización de un Sistema de Información Geográfica (SIG) y el Multicriterio propuesta por Malczewski, J. (1999) para el análisis de propuestas. Dicha metodología también fue usada por Paneque (2006) y Paegelow, M., Et al (2003) en estudios sobre gobernanza del agua y para modelación del paisaje.

Para delimitar las unidades cartográficas se usó la metodología del Levantamiento Fisiográfico (Ortíz, C., y Cuanalo, H., 1984), en la que se explica de manera puntal los pasos a seguir para generar los sistemas terrestres $\mathrm{y}$, facetas o unidades ambientales que delimitan espacialmente el área de estudio. Donde se trabaja con imágenes de satélite y fotografías aéreas, para delimitar sistemas terrestres a escalas menores y facetas con escalas más detalladas.

La metodología consiste de dos componentes principales cuya integración permite dar prioridades para el PSA; esto se refiere a que un mapa de provisión de servicios ecosistémicos es combinado con un mapa de la amenaza o riesgo a perder estos servicios. En esta metodología se le da prioridad a las diferentes actividades elegibles bajo los actuales esquemas de servicios ambientales de CONAFOR (que serían la conservación del bosque y los Servicios Ambientales Forestales, pero cada una es evaluada de forma diferente (González, B., 2011).

Dado que la información utilizada es un tanto heterogénea se debió utilizar un método que estandarizara u homogeneizara los criterios y escalas ya que estos toman valores muy diferentes entre sí. Este problema se resolvió mediante la estandarización de los criterios (Malczewski, J., 1999). En la cual todos los criterios son transformados en una escala común de medida y también el significado de los valores es evaluado en términos del objetivo a obtener. 


\subsection{Información Cartográfica}

Se utilizaron Imágenes de satélite del sensor SPOT XS, cada una abarcando una superficie de $3.600 \mathrm{~km}^{2}$ con 3 bandas del espectro electromagnético (cuadro 1). Las imágenes cubren el 100\% de la superficie abarcada por la UMAFOR 1304 que corresponde a la región del Valle del Mezquital.

Cuadro 1. Relación de imágenes utilizadas en el proceso.

\begin{tabular}{|l|l|l|}
\hline \multicolumn{1}{|c|}{ Nombre de la Imagén } & Cobertura & Fuente \\
\hline s5_586309_20080414_3a」 & $60 \times 60 \mathrm{~km}$ & CONAFOR \\
\hline s5_586310_20080409_3a」 & $60 \times 60 \mathrm{~km}$ & CONAFOR \\
\hline s5_588309_20070228_3a」 & $60 \times 60 \mathrm{~km}$ & CONAFOR \\
\hline s5_588310_20070213_3a」 & $60 \times 60 \mathrm{~km}$ & CONAFOR \\
\hline s5_589309_20071207_3a」 & $60 \times 60 \mathrm{~km}$ & CONAFOR \\
\hline s5_589310_20080404_3a」 & $60 \times 60 \mathrm{~km}$ & CONAFOR \\
\hline
\end{tabular}

Fuente: CONAFOR -Comisión Nacional Forestal-, 2012.

La cartografía temática digital es obtenida para atender las diversas variables y, se trabaja mediante el uso de Sistemas de Información Geográfica (SIG) ArcGis@ 9.2. La identificación de las áreas, del Valle del Mezquital, se llevó a cabo mediante geoprocesamientos y análisis espaciales de las coberturas cartográficas que se muestran en el Cuadro 2 . En el presente trabajo la unidad mínima cartografiable es de $10 \times 10 \mathrm{~m}$.

Cuadro 2. Relación de capas vectores utilizadas en el proceso.

\begin{tabular}{|c|c|c|}
\hline Nombre de la capa/ Estudio & Fuente & Escala \\
\hline Áreas naturales protegidas & $\begin{array}{l}\text { INEGI (conjunto de datos topográficos de Hidalgo escala } \\
\text { 1:50000) }\end{array}$ & $1: 50000$ \\
\hline Localidades & $\begin{array}{l}\text { INEGI (conjunto de datos topográficos de Hidalgo escala } \\
\text { 1:50000) }\end{array}$ & $1: 50000$ \\
\hline Curvas de nivel & $\begin{array}{l}\text { INEGI (conjunto de datos topográficos de Hidalgo escala } \\
\text { 1:50000) }\end{array}$ & $1: 50000$ \\
\hline $\begin{array}{l}\text { Uso de Suelo y Vegetación Estado de } \\
\text { Hidalgo }\end{array}$ & Gobierno del estado de Hidalgo & $1: 50000$ \\
\hline $\begin{array}{l}\text { Diseño de muestreo del Inventario } \\
\text { Estatal Forestal }\end{array}$ & Gobierno del estado de Hidalgo & $1: 50000$ \\
\hline Microcuencas UMAFOR 1304 & ERF 2010 & $1: 250000$ \\
\hline $\begin{array}{l}\text { Unidades de gestión ambiental } \\
\text { UMAFOR } 1304\end{array}$ & ERF 2010 & $1: 250000$ \\
\hline Climas Hidalgo & ERF 2010 & $1: 250000$ \\
\hline $\begin{array}{l}\text { Índice de Deforestación para el } \\
\text { Estado de Hidalgo }\end{array}$ & INE & $1: 250000$ \\
\hline
\end{tabular}

Fuente: Elaboración propia. 
La zonificación ecológica, contiene los elementos del medio natural como el relieve, clima, suelo, hidrología, vegetación, uso de la tierra, y la población. Es decir, comprende el análisis del territorio de manera integral, paso definitivo en la elaboración del diagnóstico ambiental territorial. En la zonificación se considera el paisaje como una entidad espacio temporal integrada, contribuyendo a presentar la dinámica de los procesos ecológicos y funcionamiento del paisaje; logrando así una planificación prospectiva del uso de la tierra que garantice la conservación y uso sostenido de los recursos naturales.

Para realizar una conservación correcta de la diversidad biológica es necesario ubicar las áreas más ricas, las que contienen una mayor diversidad, aquellas con altos niveles de endemismos en los grupos biológicos y aquellas que contienen especies que se encuentran en la NOM 059 que proporciona los listados de especies con estatus de protección especial. La identificación de las áreas críticas para la conservación de la biodiversidad, es urgente dadas las elevadas tasas de deforestación y cambios en el uso de suelo que ocurren en la actualidad, lo que conlleva a la perdida de importantes números de especies, así como de hábitats particulares y perdida de la funcionalidad de los ecosistemas (SEMARNAT, 2010). Asimismo, se puede perder biodiversidad de manera importante debido en parte a la falta de estrategias que permitan identificar lo que es realmente prioritario conservar.

En este estudio se consideró como información alfanumérica las tablas obtenidas de la NOM 059 (SEMARNAT, 2010), específicamente la riqueza de la fauna encontrada en la región de estudio, haciendo hincapié que por el tipo de región ambiental-climática solo se considera a la avifauna y anfibios

\subsection{Asignación de valores a criterios e indicadores}

El presente estudio retoma las propuestas de González, B. (2011), requirió de la integración de un esquema jerárquico que mediante el uso de conceptos ambientales fuera integrando criterios. Se debe señalar que para el caso de la demanda para los servicios derivados de la conservación de la biodiversidad, no se considera una demanda como tal por los usuarios dado que estos servicios son importantes únicamente por el hecho de existir de la misma, que en este caso se remite únicamente a la conservación de los ecosistemas que la proveen y ciertos usos de la tierra que no alteran significativamente la función de los mismos.

Mediante la consulta de literatura y a través de expertos en los diferentes temas, que laboran en la UMAFOR 1304, fue posible obtener el peso asignado a cada criterio e indicador, los cuales permitieron identificar espacialmente las áreas elegibles para PSA derivados de la Biodiversidad. Mediante el método de comparación "pair wise comparision" (comparación por partes) fue posible dar un peso (P) o valor a los criterios, mientras que para los indicadores se utilizó el método de "Ratio estimation procedure" (Procedimiento de estimación de porcentajes). Para ambos métodos se utilizó una escala de 0 a 100. (Aron, A.,y Aron E. 2002), ( Atil H., y Unver Y. 2001). La descripción de las variables, criterios, y peso de variables se describen en la figura 4, y los cuadros 3, 4 y 5.

De esta forma, el método Pair wise comparison se utiliza para el nivel jerárquico de más arriba porque es más preciso cuando se necesita comparar cada criterio con el restante e implica el cálculo de una proporción de consistencia de los resultados para evaluar la coherencia de comparaciones. En cambio, el Ratio estimation procedure es más fácil (simple y rápido) de utilizar por lo que se aplicó únicamente en el nivel jerárquico menor que corresponde a los indicadores de cada criterio.

Por otra parte, se utilizó el "procedimiento de rangos record" para obtener los criterios e indicadores favorables, se usó la Ecuación 1, mientras que para los criterios e indicadores de costos se utilizó la Ecuación 2. (Bechhofer, E. 1954) y (Einot, I., and Gabriel, R. 1975).

La interpretación de estas ecuaciones muestra que cuando el criterio o indicador benéfico es el más alto, el valor es más atractivo y el criterio tiene que ser maximizado; y cuando el criterio o indicador de costos es mayor, el valor es menos atractivo y el criterio tiene que minimizarse (González, B., 2011). Así pues los criterios (Figura 4) que se utilizaron para evaluar las zonas con prioridad por su importancia para la provisión de los servicios ambientales, su demanda y el riesgo o amenaza de perderlos, fueron elegidos acorde a la literatura consultada y la información disponible para la zona de estudio. 
Ecuación 1:

$$
\mathrm{x}_{\mathrm{ij}}^{\prime}=\left(\frac{\mathrm{x}_{\mathrm{ij}}-\mathrm{x}_{\mathrm{j} \text { min }}}{\mathrm{x}_{\mathrm{j} \max }-\mathrm{x}_{\mathrm{j} \min }}\right) * 100
$$

Ecuación 2:

$$
x_{i j}^{\prime}=\left(\frac{x_{j \max }-x_{i j}}{x_{j \max }-x_{j \min }}\right) * 100
$$

donde:

$X_{i j}=$ Valor del pixel estandarizado

$X_{i j}=$ Valor de todos los pixeles en el mapa

$X_{\text {jmax }}=$ Valor máximo del pixel en el mapa

$\mathrm{X}_{\mathrm{jmin}}=$ Valor mínimo del pixel en el mapa

En el caso de variables cualitativas y categóricas se utilizó la Ecuación 3, mediante la cual se le asigna un valor con rango equivalente (de forma ascendente o descendente) a cada clase o categoría.

Ecuación3:

$$
V=\left(\frac{x_{i j \max }}{n}\right)
$$

donde:

$\mathrm{V}=$ valor

Xjmax = Valor máximo del pixel en el mapa

$\mathrm{n}=$ Número de clases o categoría

\section{RESULTADOS Y DISCUSIÓN}

\subsection{Delimitación de Sistemas terrestres y facetas}

La delimitación fisiográfica de las unidades cartográficas denominadas Sistemas Terrestres y facetas, se realizó mediante la utilización de imágenes aéreas específicamente de satélite del sensor SPOT XS con tres bandas de color, se delimitaron linderos en forma de polígonos que a simple vista tuvieran características similares en su toponimia y clima, considerando en gran medida que el clima es el factor principal para la creación de zonas bióticamente homogéneas. Dichos linderos fueron hechos sobre un mosaico de imágenes de los años 2007 y 2008, con una resolución espacial de $3.600 \mathrm{~km}^{2}$ cada una. Estas imágenes permitieron, mediante el uso del sistema de Información Geográfica (SIG) antes indicado, delimitar los linderos.

En la Figura 1, se muestra el mosaico de imágenes de satélite utilizado para la UMAFOR 1304 en cobertura completa y en la Figura 2 se muestra solo el recorte que atañe específicamente al límite geopolítico de la Unidad, proceso elaborado mediante la herramienta: spatial analyst tools>extraction>extract by mask. Para realizar el proceso de unión de las imágenes se utilizó la herramienta que viene integrada en la caja de herramientas del propio ArcGis 9.2 la ruta es la siguiente: arctoolbox $>$ data management tools $>$ raster $>$ raster dataset>mosaic to new raster.

Dadas las condiciones climáticas de la Unidad de manejo, se determinó que se usaran como Sistemas Terrestres los polígonos generados por los tipos de clima, templados y semisecos, que convergen en la UMAFOR 1304, esto debido a que por defecto las características biológicas flora y fauna se ven afectadas por el factor clima. De tal modo que para el presente trabajo se ubicaron según la capa de vectores de clima del Estudio Regional Forestal con escala 1: 250.000, nueve polígonos con características climáticas propias, lo que nos da un total de nueve Sistemas Terrestres a describir. Cabe mencionar que de acuerdo a los datos 


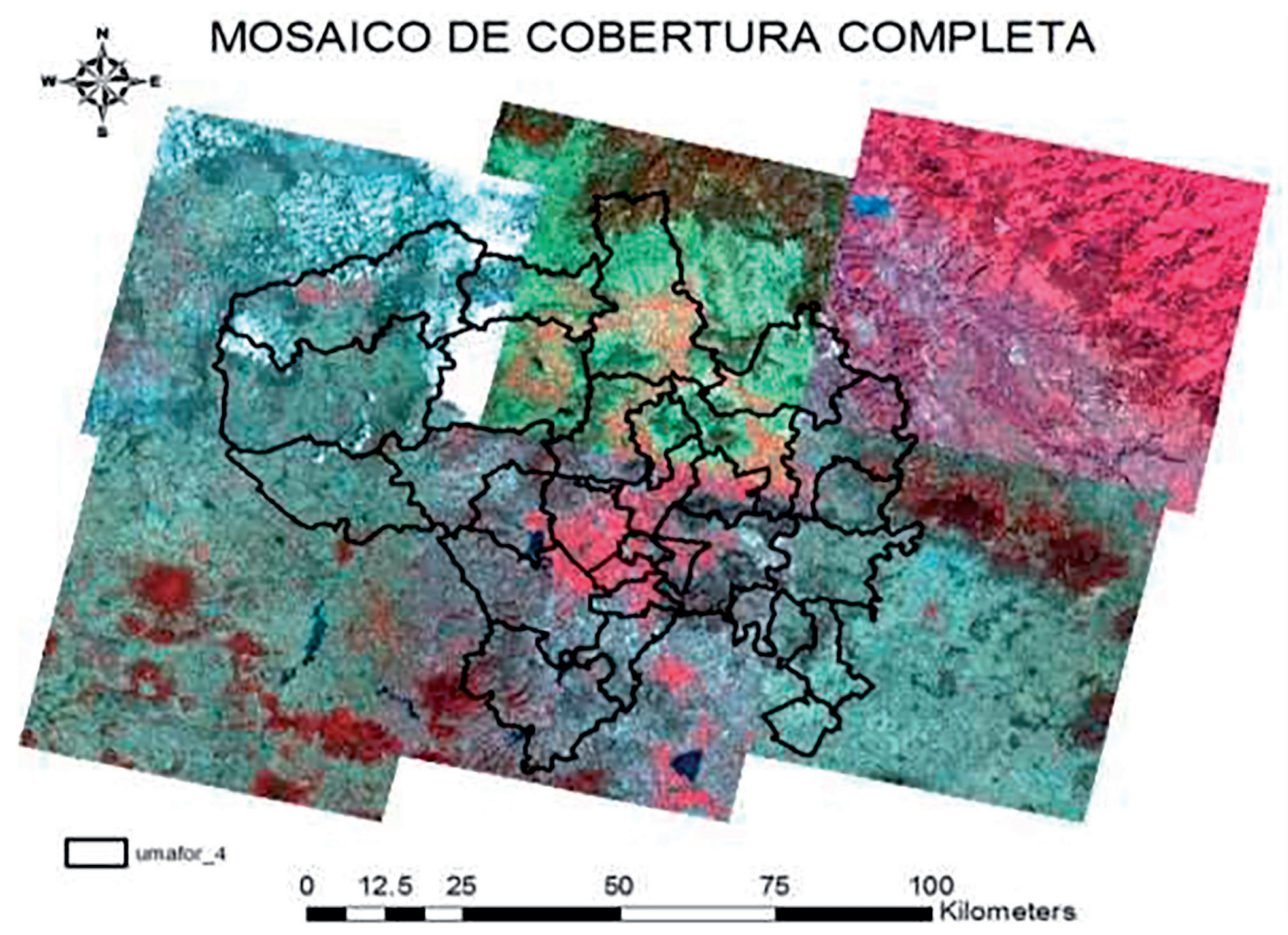

Figura 1. Mosaico de imágenes de cobertura de la UMAFOR 1304. Fuente: Elaboración propia.

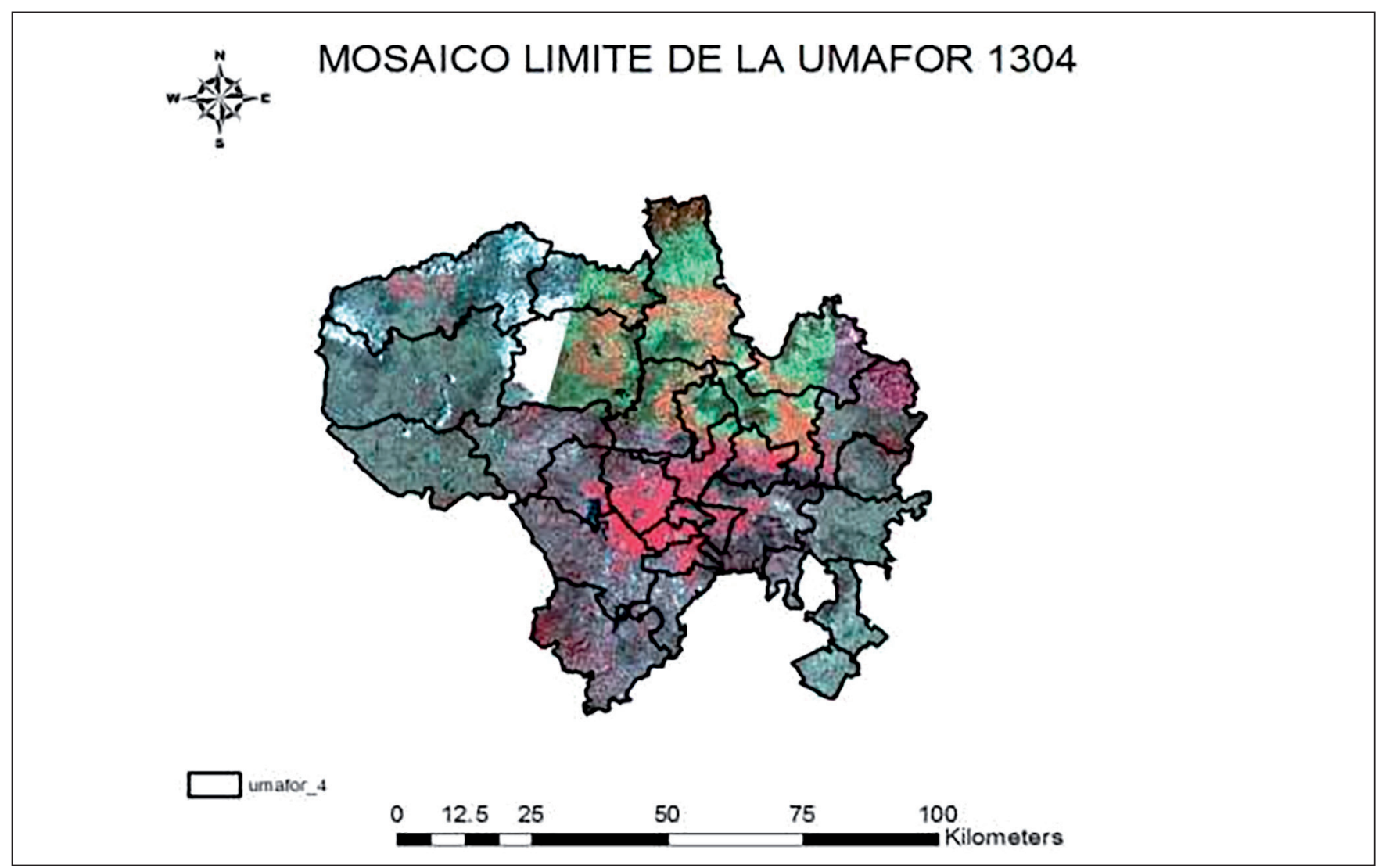

Figura 2. Recorte del mosaico de imágenes para la delimitación de la UMAFOR 1304. Fuente: Elaboración propia. 
obtenidos en cuanto a espacios naturales sólo se hace una descripción del tipo de vegetación de cada una de los 9 sistemas terrestres. También se obtuvieron 20 facetas en toda el área de la IMAFOR 1304 (Figura 3). Trabajos donde se usa la metodología del Levantamiento fisiográfico indican que ese método es adecuado para la delimitación de porciones fisiográficas, como lo indican López, F., Muñoz, D., et al (2003) usan la toposecuencia clima, suelo y vegetación para delimitar sus sistemas terrestres. En el trabajo que hicieron en la subcuenca de Zapototitlan de Salinas en el estado de puebla, México. Así mismo, Aguilar, G., y Sánchez, D. (2018) corroboran la utilidad del levantamiento fisiográfico, para la delimitación de espacios por el paisaje del relieve y la ubicación de especies vegetales en el municipio de Acámbaro, Guanajuato (México).

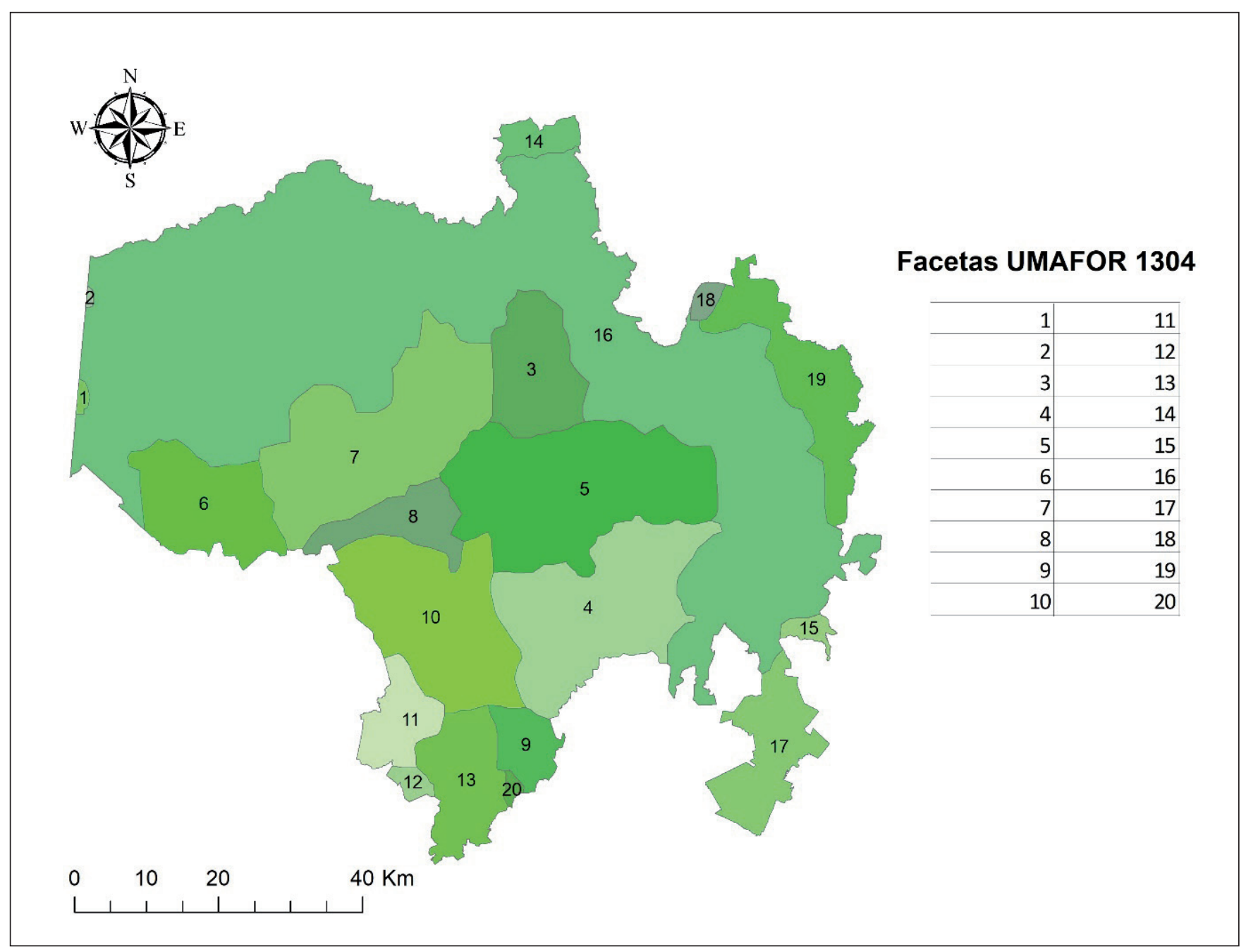

Figura 3. Facetas encontradas en la UMAFOR 1304.

Fuente: Elaboración propia.

\subsection{Determinación de áreas por la provisión de Servicios Ambientales derivados de la conservación de la biodiversidad}

La conservación de la biodiversidad corresponde a la protección de especies de flora y fauna, esta puede ser de especies en específico o desde un ámbito más generoso, es decir, la conservación de las funciones de los mismos ecosistemas (González, B., 2011). 


\subsubsection{Criterios, y pesos para priorizar áreas para el PSA por conservación de la biodiversidad}

En el esquema de la figura 4, se aprecia de forma estructural la disposición de los criterios y pesos utilizados para la priorización de áreas, por amenaza de perder los servicios eco-sistémicos, para el PSA por la conservación de la biodiversidad (González, B,2011).

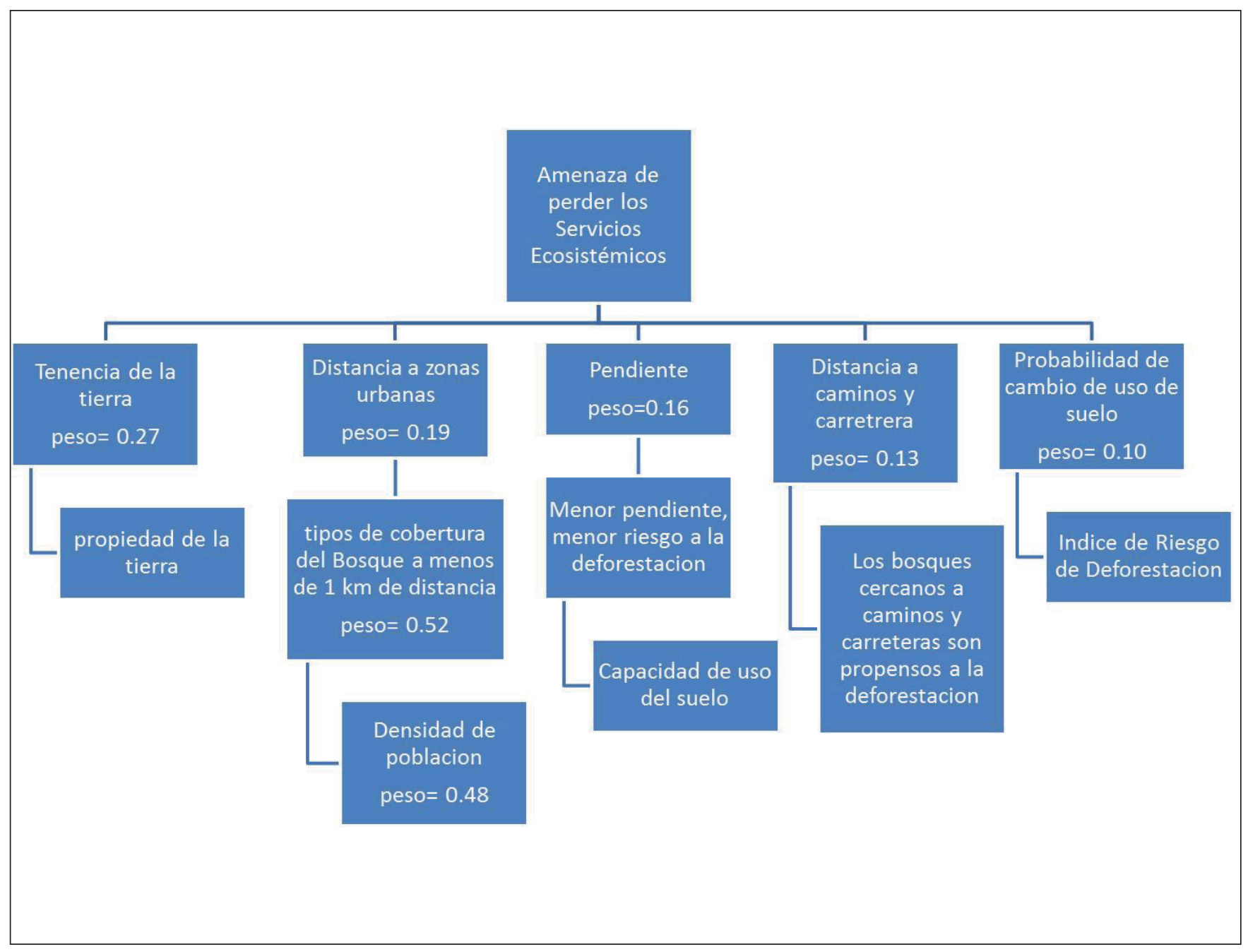

Figura 4. Esquema de criterios y pesos usados en el cálculo de la amenaza de perder los servicios ecos-sistémico. Fuente: Gonzales, B. 2011.

\subsection{Importancia para la conservación de ecosistemas en la Región}

En concordancia con el mapa de Uso de suelo y vegetación del estado de Hidalgo el cual es derivado del Inventario Estatal Forestal escala 1:50000, se reportaron 23 categorías o coberturas, de las cuales 19 son de importancia forestal (Cuadro 3, Figura 5), porque las unidades de bosque de abies, bosque de encino y selva baja caducifolia, no tienen porcentajes altos. 
Cuadro 3. Superficie de Uso de Suelo y Vegetación UMAFOR 1304 en Has.

\begin{tabular}{|c|c|c|}
\hline Agrupación & Superficie en has & $\%$ \\
\hline Área sin vegetación aparente & 832,43 & 0,13 \\
\hline Bosque de abies & 0,45 & 0 \\
\hline Bosque de abies-pino-encino & $1.008,96$ & 0,16 \\
\hline Bosque de encino & $12.621,64$ & 1,97 \\
\hline Bosque de encino-pino con vegetación secundaria & $2.446,09$ & 0,38 \\
\hline Bosque de encino con vegetación secundaria & $23.064,38$ & 3,60 \\
\hline Bosque de pino & $2.423,59$ & 0,38 \\
\hline Bosque de pino - encino (incluye encino - pino) & $3.672,20$ & 0,57 \\
\hline Bosque de pino con vegetación secundaria & 624,35 & 0,10 \\
\hline Bosque de táscate & $15.859,34$ & 2.48 \\
\hline Bosque mesofilo de montaña & 4,07 & 0 \\
\hline Cuerpo de agua & $4.313,96$ & 0,67 \\
\hline Matorral crasicaule & $118.580,31$ & 18,50 \\
\hline Matorral desértico microfilo & $1.646,67$ & 0,26 \\
\hline Matorral desértico rosetofilo & $22.949,72$ & 3,59 \\
\hline Matorral submontano & $2.874,08$ & 0,45 \\
\hline Mezquital & 510,26 & 0,08 \\
\hline Otros usos & $3.212,18$ & 0,50 \\
\hline Pastizal del alta montaña & $1.548,94$ & 0,24 \\
\hline Pastizal inducido y/o cultivado & $67.112,79$ & 10,50 \\
\hline Selva baja caducifolia & 34,34 & 0,01 \\
\hline Uso agrícola & $328.158,82$ & 51,30 \\
\hline Uso urbano & $26,516.53$ & 4,14 \\
\hline
\end{tabular}

Fuente: Elaboración propia. 


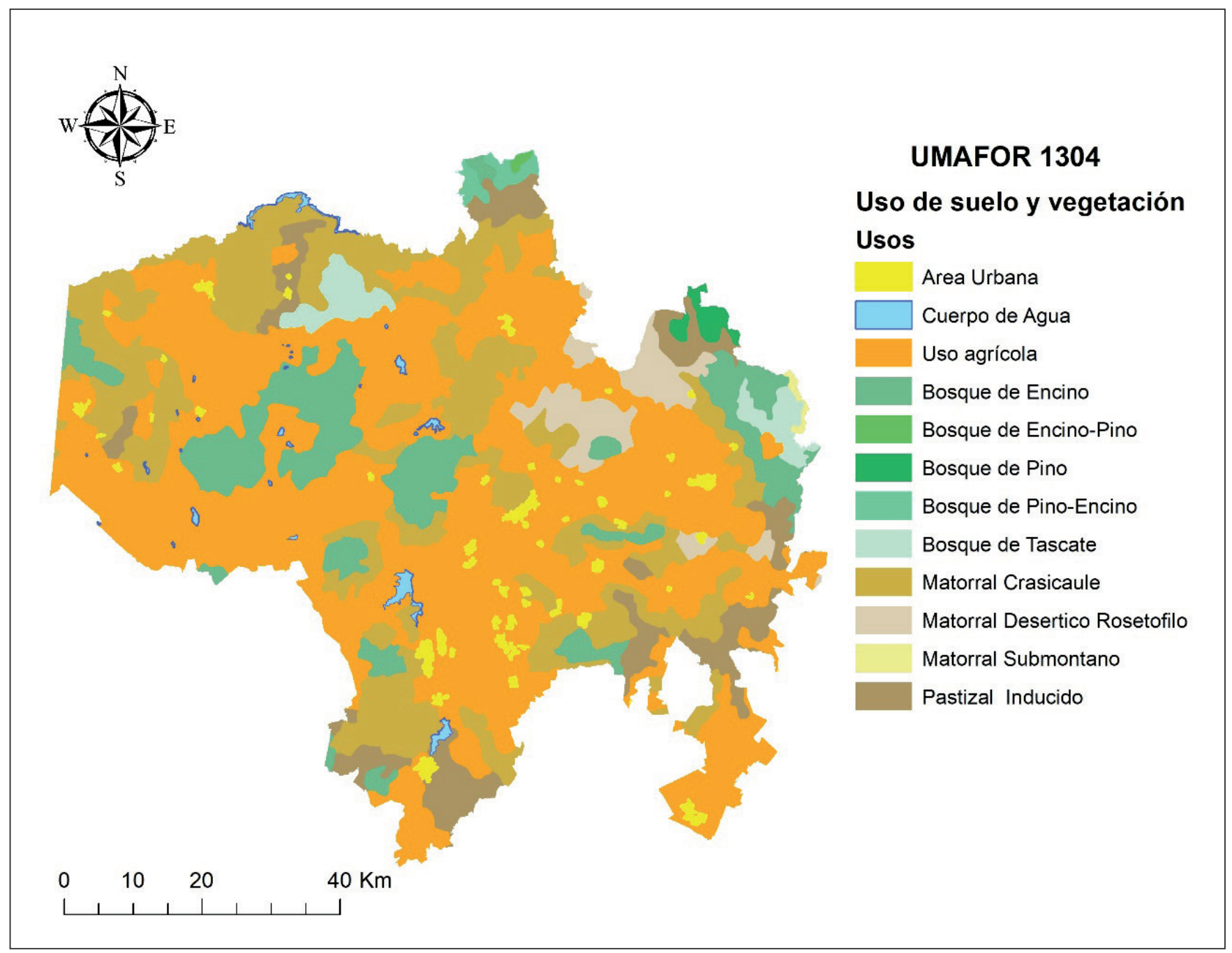

Figura 5. Uso de suelo y Vegetación. Fuente: Elaboración propia.

\subsection{Valor de los ecosistemas por su riqueza y endemismo de especies}

Flores, J., y Gérez, A. (1994) nos proporcionan una idea del número de especies endémicas y estatus de peligro de acuerdo a la NOM 059, esto con respecto a las especies que existen en el país. Trabajando bajo el supuesto de que los tipos de vegetación con mayor número de especies y endemismo son los más importantes para la protección de la Biodiversidad, entonces y mediante el uso de la Ecuación 1, se asigna a cada ecosistema un valor por la riqueza de especies y un valor por la cantidad de endemismos que se tienen, considerando que 100 es el valor más alto (Cuadro 4 y Figura 4).

En el cuadro 4, se observa que los mayores valores por endemismo son: Matorral desértico microfilo, bosque de encino, bosque mixto de pino-encino, abies, y selva baja caducifolia. Por extensión destacan: matorral desértico microfilo, bosque de pino, pastizal inducido, cuerpos de agua y uso urbano.

Al relacionar el cuadro 4 con la figura 6 , se puede destacar que por endemismo el MDM, tiene valor de 100, el BMM con valor de 94, BQ con 87, B Mixto con valor de 74 y SBC, con 59, los otros tipos de vegetación tienen valores menores de 50. La importancia y valoración de estudios sobre especies endémicas es mencionado por León, B., Pitman, N., y Roque, J. (2006) al realizar un estudio de plantas endémicas en Perú, que está influenciado por la cordillera de los Andes, con sus variaciones de altitud y, en consecuencia, de clima. Asimismo, López, F., Muñoz,D., et al. (2003) en la investigación que hicieron en la subcuenca de Zapotitlan, Puebla (México) indican como la interacción entre la geomorfología, geología, edafología y clima influyen en 
Cuadro 4. Valor de asignación de acuerdo al número de endemismos y riqueza de especies.

\begin{tabular}{|c|c|c|c|c|c|c|}
\hline $\begin{array}{l}\text { Categoría de acuerdo al inventa- } \\
\text { rio estatal forestal }\end{array}$ & $\begin{array}{l}\text { Sub-agru- } \\
\text { pación }\end{array}$ & $\begin{array}{c}\text { Agrupación final (Flores y } \\
\text { Gerez, 1994) }\end{array}$ & $\begin{array}{l}\text { Valor por } \\
\text { su No. de } \\
\text { especies }\end{array}$ & $\begin{array}{l}\text { Valor por } \\
\text { su No. de } \\
\text { endemis- } \\
\text { mos }\end{array}$ & $\begin{array}{l}\text { Valor final } \\
\text { No de sp/ } \\
\text { No de en- } \\
\text { demis-mo }\end{array}$ & $\begin{array}{l}\text { Superficie } \\
\text { (ha) }\end{array}$ \\
\hline Bosque de encino & $\mathrm{BQ}$ & bosque de encino encino & 100 & 53 & 87 & 12.622 \\
\hline Bosque mesofilo de montaña & BMM & $\begin{array}{l}\text { bosque mesofilo } \\
\text { de montaña }\end{array}$ & 90 & 75 & 94 & 4 \\
\hline Bosque de abies & $\mathrm{BC}$ & \multirow{5}{*}{ bosque de coníferas } & \multirow{5}{*}{89} & \multirow{5}{*}{40} & \multirow{5}{*}{74} & \multirow{5}{*}{22.965} \\
\hline Bosque de abies-pino-encino & $\mathrm{BC}$ & & & & & \\
\hline Bosque de pino & $\mathrm{BC}$ & & & & & \\
\hline $\begin{array}{l}\text { Bosque de pino - encino (in- } \\
\text { cluye encino - pino) }\end{array}$ & $\mathrm{BC}$ & & & & & \\
\hline Bosque de táscate & $\mathrm{BC}$ & & & & & \\
\hline Selva baja caducifolia & BT & bosque tropical & 67 & 37 & 59 & 34 \\
\hline Matorral crasicaule & MTC & \multirow{4}{*}{ matorrales } & \multirow{4}{*}{75} & \multirow{4}{*}{100} & \multirow{4}{*}{100} & \multirow{4}{*}{146.051} \\
\hline Matorral desértico microfilo & MTDM & & & & & \\
\hline Matorral desértico rosetofilo & MTDR & & & & & \\
\hline Matorral submontano & MTS & & & & & \\
\hline $\begin{array}{l}\text { Bosque de encino-pino con } \\
\text { vegetacion secundaria }\end{array}$ & BVS & \multirow{3}{*}{$\begin{array}{l}\text { bosques con vegetación } \\
\text { secundaria }\end{array}$} & \multirow{3}{*}{61} & \multirow{3}{*}{0} & \multirow{3}{*}{35} & \multirow{3}{*}{26.135} \\
\hline $\begin{array}{l}\text { Bosque de encino con vegeta- } \\
\text { ción secundaria }\end{array}$ & BVS & & & & & \\
\hline $\begin{array}{l}\text { Bosque de pino con vegeta- } \\
\text { ción Secundaria }\end{array}$ & BVS & & & & & \\
\hline Mezquital & $\mathrm{BE}$ & bosque espinoso & 44 & 10 & 31 & 510 \\
\hline Pastizal del alta montaña & PA & \multirow{2}{*}{ pastizales } & \multirow{2}{*}{34} & \multirow{2}{*}{8} & \multirow{2}{*}{24} & \multirow{2}{*}{68.662} \\
\hline Pastizal inducido y/o cultivado & PA & & & & & \\
\hline Cuerpo de agua & VA & vegetación subacuática & & & & 4.314 \\
\hline Uso agrícola & Resto & \multirow{4}{*}{ resto de ecosistemas } & \multirow{4}{*}{ * } & \multirow{4}{*}{ * } & \multirow{4}{*}{1} & \multirow{4}{*}{358.720} \\
\hline Uso urbano & Resto & & & & & \\
\hline Otros usos & Resto & & & & & \\
\hline Área sin vegetación aparente & Resto & & & & & \\
\hline
\end{tabular}

Fuente: Elaboración propia. No= número , $s p=$ especies 


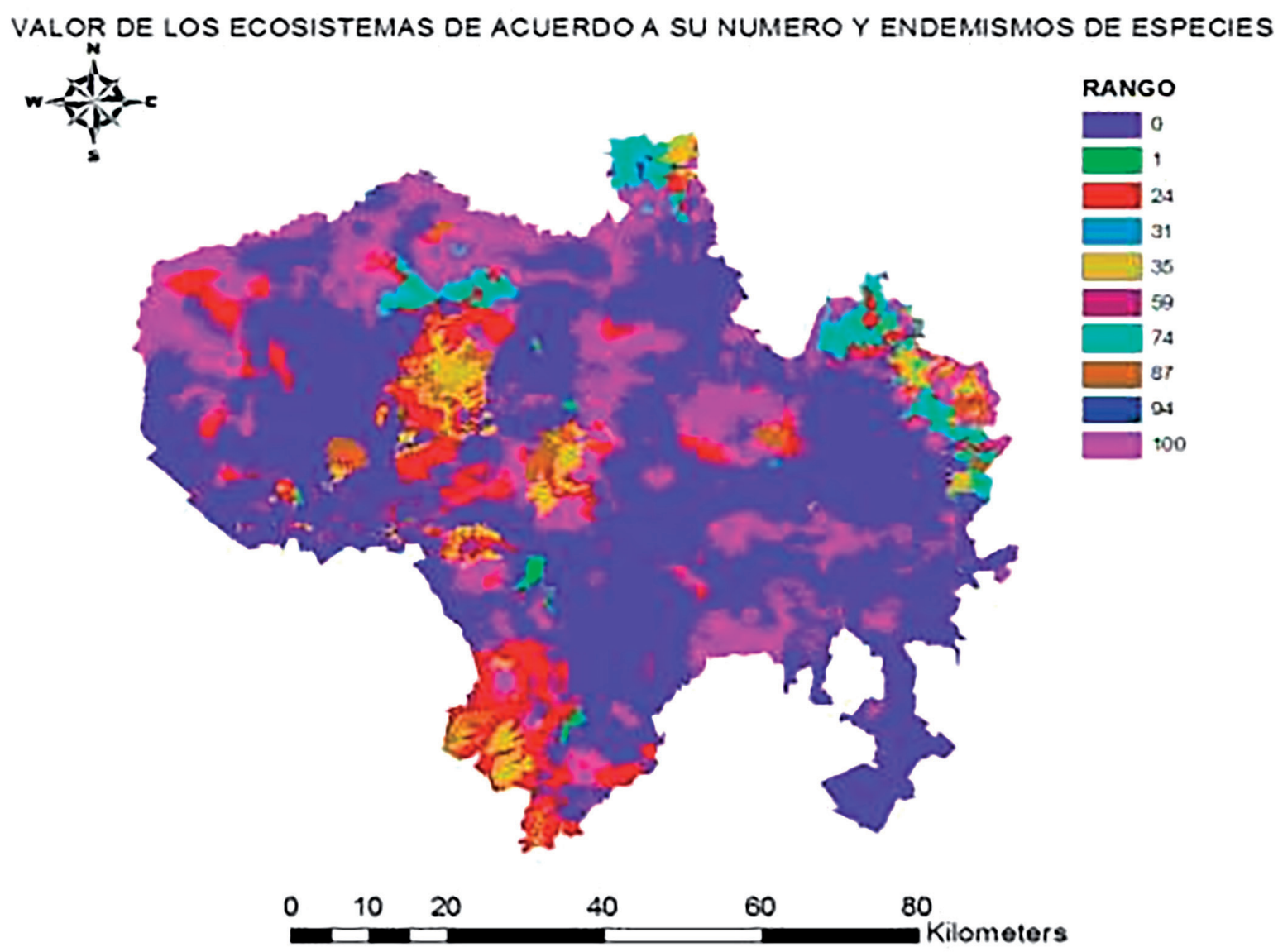

Figura 6. Valor de los ecosistemas de acuerdo a su número de especies y endemismos. Fuente: Elaboración propia.

la distribución de la vegetación endémica en cada faceta de la subcuenca estudiada. En general, la importancia del endemismo radica en el origen nativo de cada especie vegetal, ligado con su espacio geográfico a través del tiempo (Noguera, E.A., 2017).

\subsection{Superficie perdida a nivel regional}

El estado de Hidalgo pertenece a la depresión principal de la Sierra Madre Oriental. Reyes, H., et al. (2009) establece los ecosistemas de mayor pérdida de superficie en dicha depresión, en un estudio realizado que ofrece datos que van desde el año 1989 al año 2005. Tomando en cuenta esta consideración y suponiendo que los ecosistemas de mayor pérdida de superficie son prioridad en la decisión de conservación, resulta que mediante el uso de la Ecuación 1 propuesta anteriormente, los ecosistemas de mayor pérdida de superficie son los de mayor valor, para este caso se asigna el valor más alto según la escala utilizada por la metodología, es decir, 100 y este valor es el referente para definir los valores menores, los cuales serán en proporción de la pérdida de superficie y serán menores (Cuadro 5 y Figura 7). La figura 7 indica que los ecosistemas bosque tropical, bosque templado y matorral xerófilo, tienes valores de 36 a 100 , con pérdidas de vegetación importantes, y el resto de los ecosistemas también tienen un decremento importante. 
Cuadro 5. Superficie perdida de ecosistema en la UMAFOR 1304.

\begin{tabular}{|l|c|c|c|c|}
\hline \multicolumn{1}{|c|}{ Nombre de ecosistema } & $\begin{array}{c}\text { Superficie en } \\
1989, \mathrm{~km} 2\end{array}$ & $\begin{array}{c}\text { Superficie en } \\
2005, \mathrm{~km} 2\end{array}$ & \% de perdida & Valor asignado según su pérdida100 \\
\hline Bosque Tropical & 244 & 223 & 8.6 & 100 \\
\hline Matorral Xerófilo & 194 & 188 & 3.1 & 36 \\
\hline Bosque Templado & 119 & 115 & 3.4 & 40 \\
\hline Demás ecosistemas & 0 & 0 & 0 & 1 \\
\hline
\end{tabular}

Fuente: Elaboración propia.

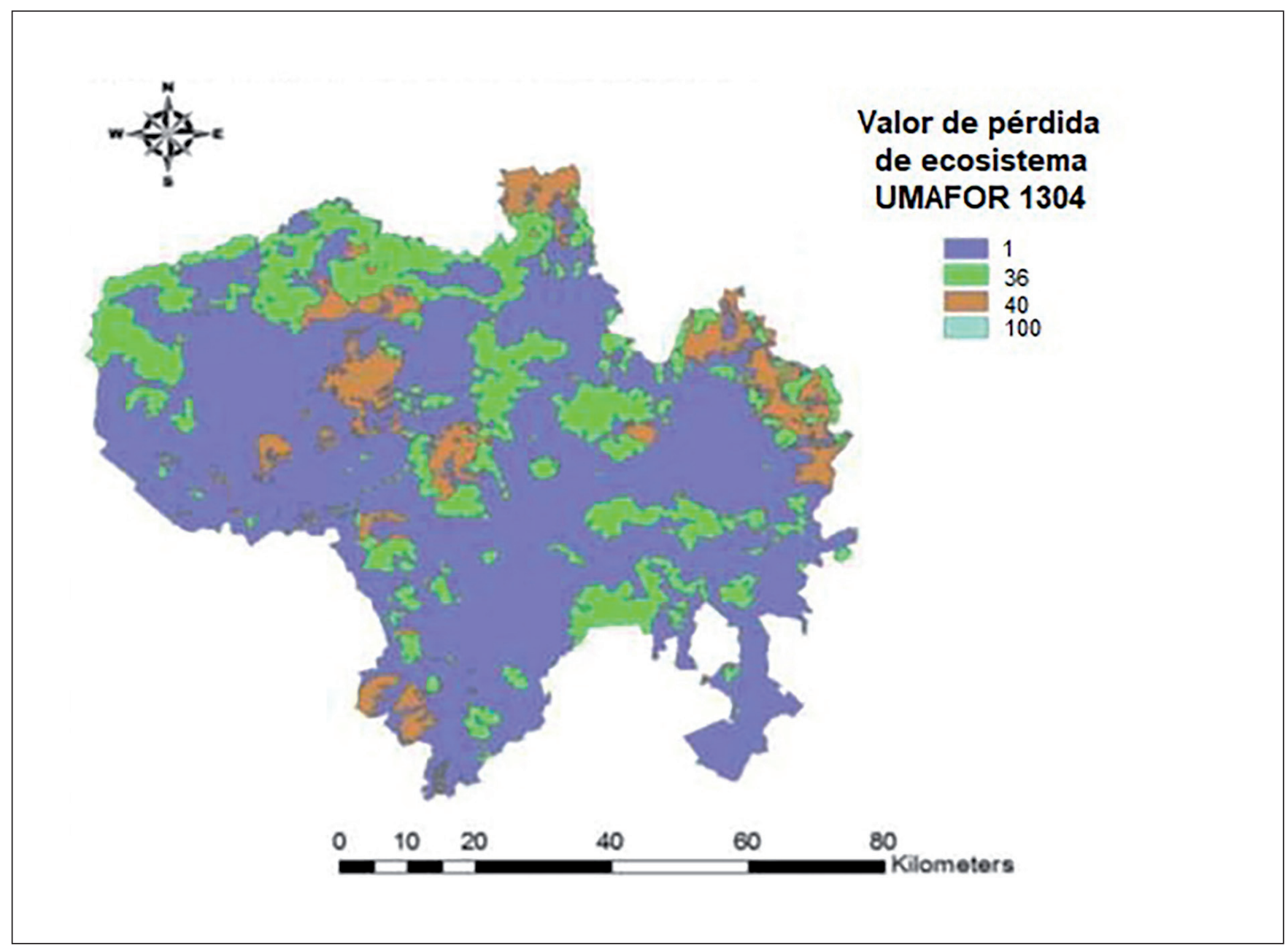

Figura 7. Mapa de valor de los ecosistemas de acuerdo a la superficie pérdida a nivel regional. Fuente: Elaboración propia.

Como resultado de la metodología propuesta se identificaron las zonas elegibles para el Pago por Servicios Ambientales dentro de la UMAFOR 1304. El mapa de la Figura 8, nos muestra gráficamente como quedaron dispuestos los polígonos que se proponen para la inclusión en el PSA dentro de UMAFOR 1304.

En el cual el rango de valor de 0-100 es significativo de que el valor más alto corresponde a zonas que tienen más valor para su conservación, esto según la metodología y la combinación de las figuras 7 y 8 con el mapa de facetas. 
Con el uso de esta metodología se identificaron las áreas elegibles de ser propuestas para el PSA de mayor prioridad, demanda y riesgo de perder los SE. Los resultados muestran que solo 911 ha de toda la superficie en la UMAFOR son áreas de alta a muy alta prioridad por la oferta y el riesgo de perder los SE derivados de la conservación de la biodiversidad (Figura 8).

La figura 8, indica que el área para el pago por servicios ambientales en toda la UMAFOR 1304, es pequeña en comparación con el espacio total, sin embargo, si se implementara el PSA con la cantidad de dinero suficiente para ayudar a los propietarios de bajos recursos, se contribuiría a preservar el ambiente y mejorar el ingreso de los dueños de los predios, como lo mencionan Sánchez A., García Rosa María, y Palma A. (2007). Así mismo se contribuiría a preservar las especies endémicas y, proteger la diversidad ecológica de las especies nativas.

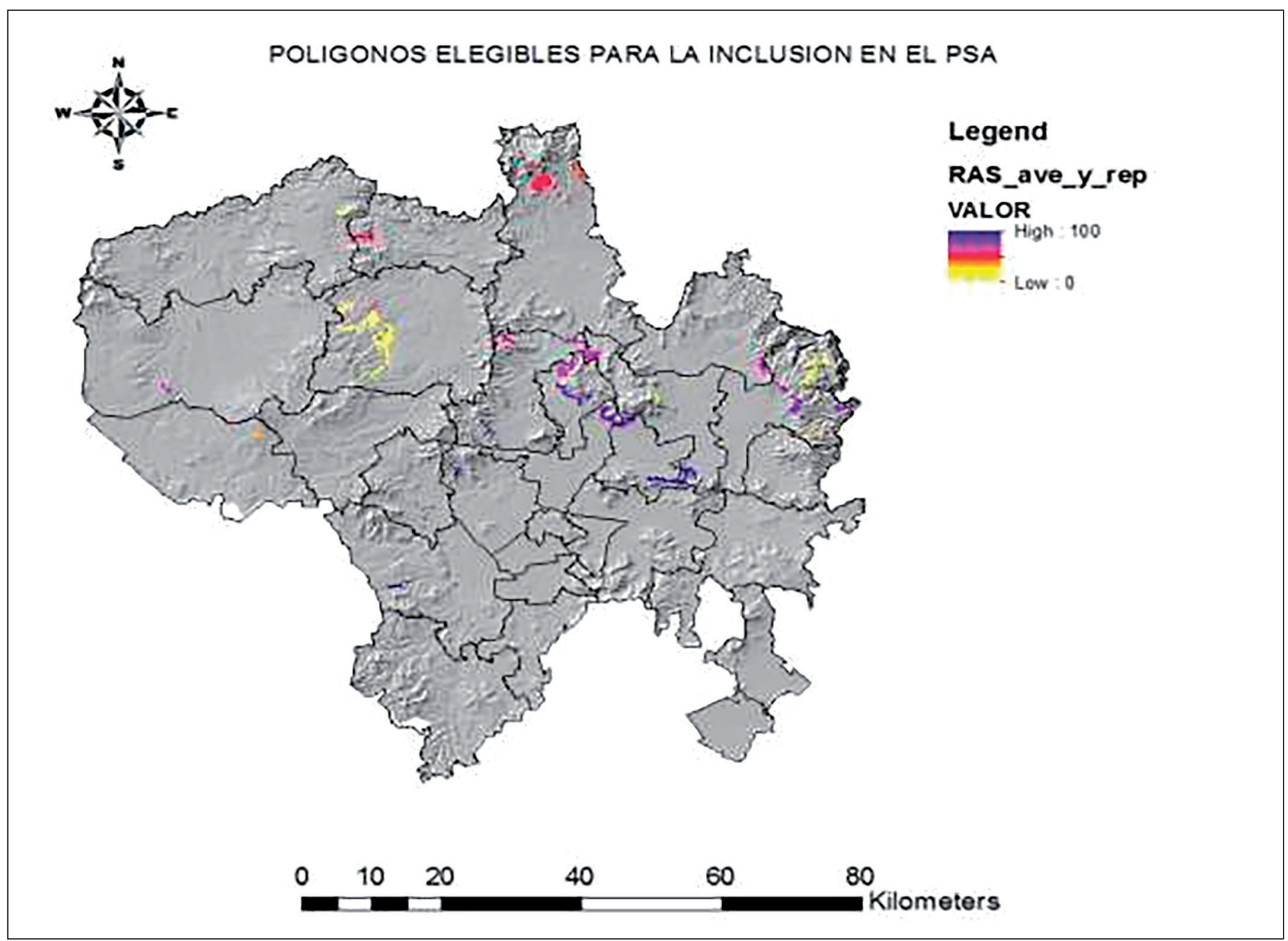

Figura 8. Mapa correspondiente a los polígonos elegibles para el PSA en la UMAFOR 1304. Fuente: Elaboración propia.

\section{CONCLUSIONES}

La metodología junto con la información técnica disponible en la UMAFOR 1304 permite ayudar a los encargados de tomar decisiones sobre la priorización de áreas para el PSA. Aunque, el procedimiento se basa únicamente en datos técnicos, se han considerado las opiniones de las partes interesadas, como los productores locales, que han sido tenidas en cuenta a través de los contactos mantenidos con técnicos de la 
UMAFOR 1304. A su vez, la metodología utilizada tiene la flexibilidad necesaria para adaptarse a cambios en las políticas institucionales y gubernamentales.

Como resultado de este trabajo, puede estimarse que en 6 de las 20 facetas es factible implementar el pago por servicios ambientales. A este respecto cabe precisar que es necesario compensar a los habitantes que viven en estos espacios con el dinero necesario como para que estos puedan al menos vivir dignamente durante el tiempo que sean utilizados sus territorios a efectos de la preservación de los ecosistemas.

Las diversas metodologías y procedimientos que usamos en este trabajo pueden ser implementadas por las gerencias estatales de CONAFOR, con el objetivo de que la toma de decisiones sobre la elección de Áreas prioritarias para el PSA se realice de una forma descentralizada y que todos los dueños de predios localizados en áreas importantes para el PSA, tengan las mismas oportunidades de participar y ser elegidos. Aunque el mecanismo con el cual la CONAFOR podría implementar esta metodología en la toma de decisiones, implicaría una modificación de sus procedimientos administrativos actuales.

Los estudios sobre los servicios ambientales que proporcionan los bosques es relativamente reciente. Domínguez, O., Betancourt, Y. y Rodríguez, G. (2007) indican que, en Cuba en 2004, las instituciones y el pueblo en general desconocen la importancia de los SA, que proporciona el bosque y que se han venido proporcionando de manera espontánea. Además, mencionan que no hay trabajos sobre su valoración económica. Por lo anterior, es relevante lo que se hace en México. Sin embargo, para no perder los SE, es necesario que el PSA, sea mayor a lo autorizado por la CONAFOR, como lo indican Sánchez A., García R M., y Palma A. (2007) ya que tanto el PSA, como el PSAH, son importantes para conservar y preservar los ecosistemas de México.

\section{REFERENCIAS}

Aguilar, G., \& Sánchez, D. (2018). Regionalización del paisaje para el ordenamiento del territorio en el municipio de Acámbaro, Gunajuato. En J. M. Rodriguez, y V. M. Ortega, El Ordenamiento Territorial y Ecológico: Hacia una Visión Integradora (págs. 394-411). Guanajuato: Universidad de Guanajuato.

Ancira-Sánchez, L. (2015). Utilización de imágenes de satélite en el manejo forestal del noreste de México. Madera y Bosques, 21(1), 77-91. doi: https://doi.org/10.21829/myb.2015.211434

Aron, A., \& Aron, E. (2002). Statistics for the Behavioral and Social Sciences. New York: Prentice Hall.

Ayala, F., Espejel, I., Eaton, R., \& Daessle, W. (2011). Propuesta de evaluaciòn ràpida de servicios ambientales hidrològicos en zonas aridas.

Bechhofer, E. (1954). A single-sample multiple decision procedure for ranking means of normal populations with known variances. Ann. Math. Stat. 25, 16-39. doi: https://doi.org/10.1214/aoms/1177728845

Camacho, I. (2011). Ecologia y medio ambiente. Mèxico D F.: S.T.

Campos, J., Alpízar, F., Louman, B., \& Parrotta, J. (2005). An Integrated Approach to Forest Ecosystem Services. En G. A. Mery.

Chafla, P., \& Cerón, P. (2016). Pago por servicios ambientales en el sector del agua: el Fondo para la Protección de Agua. Tecnología y Ciencias del Agua, 21-40.

CIFOR. (2006). Los principios básicos del pago por servicios ambientales, policy research proyects, reports. Los principios básicos del pago por servicios ambientales. Indonecia: Research Institutes Bogor.

CIFOR. (2007). Annual Report: forest management,forest policy,research projects, reports, research institutes. Indonencia: Bogor.

Colegio de posgraduados. (2008). Evaluación Externa de los Apoyos de los Servicios Ambientales ejercicio fiscal 2007. Montecillos: Conafor-SAGARPA.

CONAFOR. (2003). "documento de Posición Institucional- PROÁRBOL- Programa de Pago por Servicios Ambientales HidrológiCOS (PSAH) y Programa para Desarrollar el Mercado de Servicios Ambientales por Captura de Carbono y los Derivados de la Biodiversidad y para fomentar el es. Mèxico DF: SAGARPA.

CONAFOR. (2012). Descripción técnica de la clasificación de la Zona Elegible en áreas de pago diferenciado, para el Concepto de Apoyo B2. Servicios Ambientales de ProÁrbol, correspondiente a la Convocatoria 2012. Mèxico DF: SAGARPA.

CONAFOR. (2012). Inventario Nacional Forestal 2004-2009. Zapopan Jalisco: SAGARPA. 
CONAGUA. (15 de Enero de 2015). Sistema Nacional de Información del Agua (SINA)" - Estadísticas del agua en Mèxico 2008. Recuperado de: http://www.conagua.gob.mx

CONANP. (2010). Pago Por Servicios Ambientales en Áreas Naturales Protegidas. Dirección General de Operación Regional Comisión Nacional de Áreas Naturales Protegidas". Mèxico DF: SEMARNAP.

Costanza, R., d'Arge, R., de Groot, R., Farber, S., Grasso, M., Hannon, B., Van den Belt, M. (1997). The value of the world's ecosystem services and natural capital. Nature, 387, 253-260. doi: https://doi.org/10.1038/387253a0

Diario Oficial de la Federación, (DOF). (1988). Ley General del Equilibrio Ecológico y la Protección al Ambiente. Última reforma publicada DOF 16-05-2008. Mèxico DF: Congreso de la Uniòn.

DOF. (2011). Ley sobre la compensación ambiental por el cambio de uso de suelo en terrenos forestales. Mèxico DF: Congreso de la uniòn.

Domínguez, O., Betancourt, Y., \& y Rodríguez, G. (2007). Metodología para la elaboración de un sistema de pagos por servicios ambientales forestales. En M. de Agricultura: Cuarto Congreso forestal de Cuba (págs. 75-76). La Habana: Ministerio de la agricultura de Cuba.

Einot, I., \& and Gabriel, R. (1975). A study of the powers of several methods of multiple comparisons. Am. Stat. Assoc, 574583. doi: https://doi.org/10.1080/01621459.1975.10482474

FAO. (2005). State of the World Forest 2005. Roma: ONU.

Farber, S., Costanza, R., \& Wilson, M. (2002). Economic and ecological concepts for valuing Ecosystem services. Ecological Economics, 375-392. doi: https://doi.org/10.1016/S0921-8009(02)00088-5

Flores, J., \& y Gerez, A. (1994). Anfibios, reptiles, aves y mamíferos. Especies endémicas restringidas al tipo de vegetación. Mèxico DF: Semarnap.

Francisco, F., Muñoz, D., Hernández, M., Alfonso Soler, A., \& Castillo, M. y. (2003). Análisis integral de la toposecuencia y su influencia en la distribución de la vegetación y la degradación del suelo en la Subcuenca de Zapotitlán Salinas, Puebla. Boletín de la Sociedad Geologíca Mexicana, 19-41. doi: https://doi.org/10.18268/BSGM2003v56n1a3

Gobierno de los Estados Unidos Mexicanos. (2009). Diario Oficial de la Federación. DOF. Mèxico DF: DOF.

Gómez, J. M. (2007). La captura de carbono como servicio ambiental en la comunidad Los y Pescadores del Municipio de Tepehuanes, Durango. En A. S. (Editor), Manejo de los Recursos Naturales en México, UACh., México (pp. 67-92). Texcoco, México: UACh.

González, B. (2011). Identificación espacial de áreas prioritarias para el pago por servicios ambientales (PSA) hidrológicos y derivados de la conservación de la biodiversidad en la Sierra Madre Oriental. San Luis Potosì: UASLP.

Groombridge, B. (1992). Biological diversity; Species diversity; Biological diversity conservation. doi: https://doi. org/10.1007/978-94-011-2282-5_15

Imbach, P. (2005). Priority areas for payment for environmental services (PES) in Costa Rica. Turrialba: UNA-Costa Rica.

INEGI. (1992). Síntesis Geográfica del estado de Hidalgo. México, DF: SPP.

INEGI. (2005). Anuario Estadístico de Hidalgo. Aguascalientes Ags: SPP.

León, B., \& P. N. (2006). Introducción a las plantas endémicas de Perú. Perú. Biología, 9-22.

Macip-Ríos R, y. R. (2013). Payment for environmental services in mexico. an alternative for biodiversity conservation and development. Biocyt, 89-107.

Malczewski, J. (1999). GIS and Multicriteria decision analysis. New York: John Wiley \& Sons.

Naidu, R. S. (2006). "Managing Arsenic in the Environment: From soil to human health. Victoria: CSIRO Publishing. doi: https://doi.org/10.1071/9780643093515

Noguera, E. A. (2017). El endemismo: diferenciación del término, métodos y aplicaciones. Acta Zoológica Mexicana, 89107.

Ortiz, C., \& Cuanalo, H. (1984). Metodología del Levantamiento Fisiográfico, un sistema de clasificación de tierra. Texcoco, México: COLPOS.

Paegelow, M., \& Camacho, M. y. (2003). Cadenas de markov, evaluación multicriterio y evaluación multiobjetivo para la modelización prospectiva del paisaje. Geo Focus, 22-24.

Pagiola, S. (2008). Payments for environmental services in Costa Rica. Ecological Economics. Elsevier, 712-724. doi: https://doi.org/10.1016/j.ecolecon.2007.07.033

Paneque, P., Corral, S. G., \& Del Moral (2006). Participative multi-criteria analysis for the evaluation of water governance alternatives. A case in the Costa del Sol (Málaga). Ecological Economics, 990-1005. 
Rojas-López, O., M, G. G., Gómez-Guerrero, M., \& Romo Lozano, J. (2012). La renta de la tierra y el pago de servicios ambientales en la Sierra norte de Puebla. Revista Mexicana de Ciencias Forestales, 41-56. doi: https://doi.org/10.29298/ rmcf.v3i11.516

Rzedowski, J. (2006). Vegetación de México. México, DF: Limusa.

Sánchez, A., G. R., \& y Palma, A. (2007). Producción de agua en bosques de montaña: balance hidríco, PSAH, y su valoración económica. En A.S.G (Coord.) Manejo de los Recursos Naturales en México (pp. 41-66). Texcoco, México: UACh.

SEMARNAT. (2010). Norma Oficial Mexicana NOM-059-SEMARNAT-2010, Protección ambiental-Especies nativas de México de flora y fauna silvestres-categorías de riesgo y especificaciones para su inclusión, exclusión o cambio de lista de especies. México, DF: SEMANRNAT.

Valdez-Lazalde, J., Aguirre-Salado, C., \& Ángeles-Pérez, G. (2011). Análisis de los cambios en el uso del suelo en la cuenca del río metztitlán (México) usando imágenes de satélite: 1985-2007. Revista Chapingo. Serie Ciencias Forestales y del Ambiente, 313-322. doi: https://doi.org/10.5154/r.rchscfa.2010.06.041

Wunder, S. (2006). Pagos por servicios ambientales: Principios básicos esenciales. Centro de Investigación Forestal (CIFOR. Indonesia: CIFOR. 